\title{
RAPID REPORT
}

\section{INDUCTION OF HEAT SHOCK PROTEIN 70 REDUCES THE ALTERATION OF STRIATAL ELECTRICAL ACTIVITY CAUSED BY MITOCHONDRIAL IMPAIRMENT}

\author{
M. TANTUCCI, ${ }^{a, b}$ G. MARIUCCI, ${ }^{c}$ E. TAHA, ${ }^{c}$ \\ C. SPACCATINI, ${ }^{a, b}$ A. TOZZI, ${ }^{a, b}$ E. LUCHETTI, ${ }^{a, b}$ \\ P. CALABRESI ${ }^{a, b}$ AND M. V. AMBROSINIc* \\ ${ }^{a}$ Dipartimento di Specialità Medico-Chirurgiche e Sanità Pubblica, \\ Clinica Neurologica, Università degli Studi di Perugia, Via Enrico dal \\ Pozzo, 06126 Perugia, Italy \\ ${ }^{b}$ IRCCS, Fondazione Santa Lucia, 00143 Roma, Italy \\ 'Dipartimento di Medicina Sperimentale e Scienze Biochimiche, Sezi- \\ one di Biologia Cellulare e Molecolare, Università degli Studi di Peru- \\ gia, Via del Giochetto, 06123, Perugia, Italy
}

\begin{abstract}
Since mild thermal stress seems to exert neuroprotection via induction of heat-shock protein $70 \mathrm{kDa}$ (hsp70), we tested whether hsp70 would preserve striatal bioelectrical activity under conditions of mitochondrial impairment. Corticostriatal slices from rats that had undergone mild thermal stress were exposed to either rotenone or 3-nitropropionic acid (3-NP), that selectively inhibits mitochondrial complex I and complex II, respectively. Rotenone is utilized to obtain an experimental model of Parkinson's disease while 3-NP replicates Huntington's disease phenotype in experimental animals. The cerebral hsp70 increase did not alter field potential amplitude of the slices but partially protected them against rotenone-induced neurotoxicity. Similarly, induction of hsp70 had also a partial neuroprotective effect on the neurotoxicity caused by 3-NP on striatal field potential. Since rotenone and 3-NP treatments mimic the mitochondrial impairment and oxidative stress that contribute to development of Parkinson's disease and Huntington's disease, these data suggest that induction of hsp70 might represent a possible neuroprotective mechanism against the pathophysiological chain of events implicated in these neurodegenerative disorders. (c) 2009 IBRO. Published by Elsevier Ltd. All rights reserved.
\end{abstract}

Key words: hsp70, mitochondrial impairment, 3-NP, rotenone, striatal neurotoxicity.

In mammals, the heat shock protein $70 \mathrm{kDa}$ family (HSP70) consists of several members some of which, such as constitutive heat shock protein $70 \mathrm{kDa}$ (hsc70; synonymous to hsp73), are constitutively expressed while inducible heat shock protein $70 \mathrm{kDa}$ (hsp70; synonymous to hsp72) is induced by stresses. Both of them facilitate nascent protein

${ }^{*}$ Correspondence to: M. V. Ambrosini, Dipartimento di Medicina Sperimentale e Scienze Biochimiche, Via del Giochetto, 06123, Perugia, Italy. Tel: +39-0755857479; fax: +39-0755857478.

E-mail address: ambrosini.mv@unipg.it (M. V. Ambrosini).

Abbreviations: HS, heat shocked; hsp70 (synonymous to Hsp72), inducible heat shock protein $70 \mathrm{kDa}$; PD, Parkinson's disease; 3-NP, 3-nitropropionic acid. folding, refolding or degradation of abnormal proteins, transport and translocation across membranes of newly-synthesized proteins into intracellular compartments, and inhibit formation of incorrect protein aggregates (Craig, 1993). hsp70 Induction by mild hyperthermia or pharmacological agents seems to exert neuroprotection in cerebral ischemia and in neurodegeneration (Ota et al., 2000; Sittler et al., 2001; Lu et al., 2002; Ren et al., 2004).

In this study, we tested whether overexpression of hsp70, induced by mild heat shock, could prevent electrophysiological alterations in two in vitro models of neurotoxicity obtained by administration of rotenone and 3-nitropropionic acid (3-NP), which selectively inhibit mitochondrial complex I (Betarbet et al., 2000; Costa et al., 2008) and complex II (Calabresi et al., 2001; Centonze et al., 2006; Saulle et al., 2004), respectively. Rotenone is utilized to obtain an experimental model of Parkinson's disease (PD) (Betarbet et al., 2000). Moreover, it has also been postulated that rotenone not only acts as a dopaminergic toxin but also generates lesions that are not limited to midbrain dopaminergic neurons. In fact, rotenone intoxication in vivo has been suggested to model atypical forms of PD such as progressive supranuclear palsy (Hirsch et al., 2003).

3-NP replicates mitochondrial dysfunction and striatal lesions observed in Huntington's disease (HD) (Brouillet et al., 2005; Di Filippo et al., 2006).

Our findings suggest that mild heat shock and resulting hsp70 induction do not alter basal electrophysiological properties of corticostriatal slices while they partially protect the electrical activity recorded from slices exposed to either rotenone or 3-NP.

\section{EXPERIMENTAL PROCEDURES}

\section{Animals and heat shock preconditioning}

Male Wistar rats ( $n=18,4-6$ weeks, Charles River, Calco, Italy) were randomly assigned to either heat-shocked (HS; $n=10)$ or control $(n=8)$ groups. To induce heat stress, the rats were exposed to a temperature of $43{ }^{\circ} \mathrm{C}$ until body temperature reached $41.5-42{ }^{\circ} \mathrm{C}$. Then they were allowed to recover their normal body temperature at room temperature. Four hours later, they were sacrificed by decapitation under chloral hydrate $(400 \mathrm{mg} / \mathrm{kg})$ anesthesia.

Brains were quickly removed and corticostriatal coronal slices (270 $\mu \mathrm{m}$ thick) were cut according to a method previously described (Calabresi et al., 1998, 2001; Centonze et al., 2006; Tozzi et al., 2007; Costa et al., 2008). Control animals underwent the same experimental procedure without being HS.

0306-4522/09 \$ - see front matter @ 2009 IBRO. Published by Elsevier Ltd. All rights reserved. doi:10.1016/j.neuroscience.2009.06.070 
The study was approved by the Bioethical Committee of the University of Perugia and was conducted according to the European Communities Council Directive of November 1986 (86/609/ EEC). Every effort was made to minimize the number of animals used and their suffering.

\section{Electrophysiological study}

The brain slices were transferred to a maintenance chamber and submerged in a continuously flowing Kreb's solution ( $\mathrm{pH} 7.4)$ containing (in mM): $126 \mathrm{NaCl}, 2.5 \mathrm{KCl}, 1.2 \mathrm{MgCl}_{2}, 1.2 \mathrm{NaH}_{2} \mathrm{PO}_{4}, 2.4$ $\mathrm{CaCl}_{2}, 10$ glucose, and $25 \mathrm{NaHCO}_{3}$ and in which a mixture of $95 \%$ $\mathrm{O}_{2}$ and $5 \% \mathrm{CO}_{2}$ bubbled. Each slice was transferred to a recording chamber and submerged in the flowing Kreb's solution $\left(32-33^{\circ} \mathrm{C}\right.$; 2.4-2.6 $\mathrm{ml} / \mathrm{min}$ ) bubbled with $95 \% \mathrm{O}_{2}$ and $5 \% \mathrm{CO}_{2}$. Rotenone (SigmaAldrich, Milan, Italy) was first dissolved in dimethylsulfoxide (DMSO), (Merck KGaA, Darmstadt, Germany) and then diluted in Kreb's solution to a final concentration of $1 \mu \mathrm{M}$. Instead, 3-NP (Sigma-Aldrich, Milan, Italy) was directly dissolved in a $\mathrm{Mg}^{2+}$-free Kreb's solution to a final concentration of $10 \mathrm{mM}$. Drugs were bath-applied by switching the solution to one containing a known concentration of drugs (Tozzi et al., 2007). For patch-clamp recordings we used a method previously described (Costa et al., 2008).

Extracellular recordings of striatal neurons were carried out by using microelectrodes pulled from borosilicate glass pipettes backfilled with $2 \mathrm{M} \mathrm{NaCl}$ (15-20 M 2 ). An Axoclamp 2B amplifier (Axon Instruments, Foster City, CA, USA) was used for extracellular recordings.

Field potentials were evoked every $10 \mathrm{~s}$ by means of bipolar electrodes connected to a stimulator unit (Grass Telefactor, West Warwick, RI, USA). The stimulating electrodes were located in the corpus callosum area to activate corticostriatal fibers. Recording electrodes were placed within the striatum, located 1-2 $\mathrm{mm}$ from the white matter. The field potential amplitude was defined as the average of the amplitude from the first positive peak to the negative one and the amplitude from the negative peak to the second positive one.

Quantitative data were expressed as a percentage of the field potential amplitudes with respect to the basal control amplitude values, the latter representing the mean of responses recorded during a stable period (15 to $20 \mathrm{~min}$ ). Off-line analysis was performed using Clampfit (Axon Instruments, Foster City, CA, USA) and Microcal Origin (Northampton, MA, USA) software. For the input-output curve, a stimulus of increasing voltage intensity and constant duration $(200 \mu \mathrm{s})$ was delivered every $5 \mathrm{~s}$.

\section{Western blot analysis}

Pools of corticostriatal slices from each HS and each control animal were homogenized to determine levels of hsp70 by Western blot analysis using a mouse monoclonal anti-hsp70 (SPA-810, StressGen Biotechnologies, Victoria, Canada) according to a method previously described (Mariucci et al., 2007).

\section{Statistical analysis}

Data are presented as means \pm SEM. Two-way ANOVA and Bonferroni's post hoc test were used for statistical analysis of electrophysiological data. Statistical differences between densitometric data were analyzed by Mann-Whitney U-test.

\section{RESULTS}

Medium spiny neurons were recorded from control $(n=8)$ and from HS $(n=8)$ slices by conventional whole-cell patch-clamp
A

Control

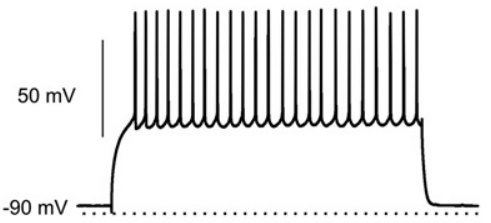

$200 \mathrm{pA}$

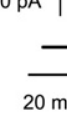

B

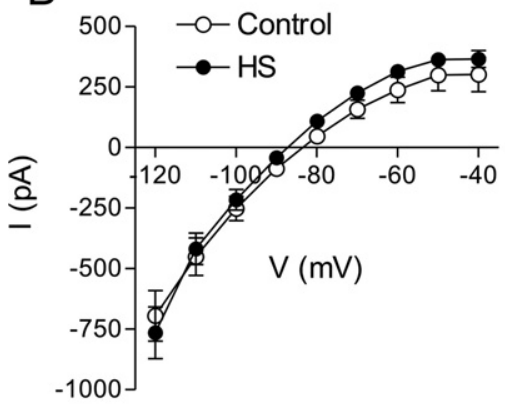

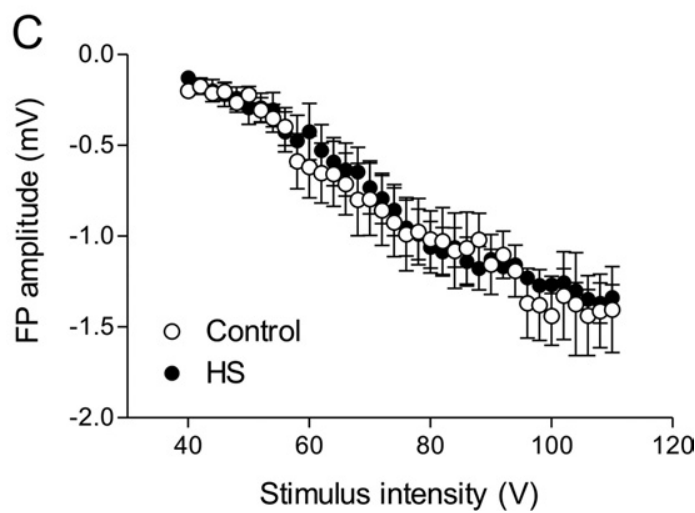

Fig. 1. Hsp70 overexpression does not affect basal electrophysiological properties recorded from corticostriatal slice preparations. (A) Voltage traces (upper) show firing discharge induced by positive current steps (lower) and recorded from two medium spiny neurons during whole cell patch clamp recordings in slices from control (left) and HS rats (right). (B) Current voltage plots obtained from several medium spiny neurons recorded from control and HS rats. (C) Input-output curves representing extracellularly recorded field potential amplitude at different intensities of stimulation both in control and HS animals. 
recordings (Costa et al., 2008) in order to explore possible differences in the electrophysiological properties of these neurons. We performed current-voltage relationship and, as shown in Fig. 1A, B, the plots represent similar curves in the two groups suggesting no differences in their intrinsic electrical properties $(P>0.05)$. As shown in the input-output curves presented in Fig. 1C, field potential amplitudes were similar when the slices, obtained either from control animals or from HS rats, were stimulated with increasing stimulus intensities (control vs. HS, $P>0.05, n=9$ and $n=10$, respectively).

The addition of rotenone $(1 \mu \mathrm{M})$ to the perfusion solution caused a rapid continuous reduction of corticostriatal field potential amplitude which was almost completely abolished $(-90 \%)$ within $25 \mathrm{~min}$ in the controls $(n=8)$ (Fig. $2 A, B)$. The field potential reduction, relative to the HS slices, showed a different time course (Fig. 2A, B). Indeed, $15 \mathrm{~min}$ after the onset of rotenone application, the slices $(n=10)$ from HS animals still presented a field potential amplitude of about $90 \%$ while in the control ones it was about $57 \%(P<0.01)$. Moreover, in the HS slices, the amplitude of field potentials at 20 and 25 min was still higher than controls $(P<0.01$ and $P<0.05$, respectively). As expected, cerebral slices from HS rats expressed higher levels of hsp70, with respect to euthermic controls (Fig. 2C, D).

In the presence of 3-NP, within $10 \mathrm{~min}$, the control slices $(n=10)$ showed a reduction of about $50 \%$ of the basal value of the field potential amplitude, which reached its maximum reduction (-93\% in mean) within $35 \mathrm{~min}$ (Fig.
3 A, B). Conversely, HS slices $(n=10)$ showed a field potential amplitude that was significantly higher at every recording time. In particular, $35 \mathrm{~min}$ after the addition of 3-NP, when the field potential of the controls was completely abolished, the amplitude of field potential of the HS slices was still about $50 \%$ of its basal value. Also the 3-NP-treated slices from HS rats had levels of hsp70 that were higher than those from the euthermic controls (Fig. 3C, D).

Taken together our data indicate that while overexpression of hsp70 did not modify the electrophysiological properties of the corticostriatal slices, it seemed to confer resistance to inhibition of both complex I and complex II of mitochondrial respiratory chain.

\section{DISCUSSION}

Numerous studies demonstrate that mild heat shock confers cerebral cytoprotection against different stressors via induction of heat shock proteins (HSPs). Actually, mild heat shock leads to induction of stress proteins other than hsp70, such as hsp25/27 and hsp90. These proteins are expressed at different time scales and they also have a specific localization, suggesting that they have distinct roles during stress response and they may cooperatively contribute to the protection of neuronal cells from stressful insult (Kabakov and Gabai, 1995; Nishizawa and Nagata, 1999).

A possible neuroprotective role of hsp70 has never been addressed by utilizing an electrophysiological approach. In
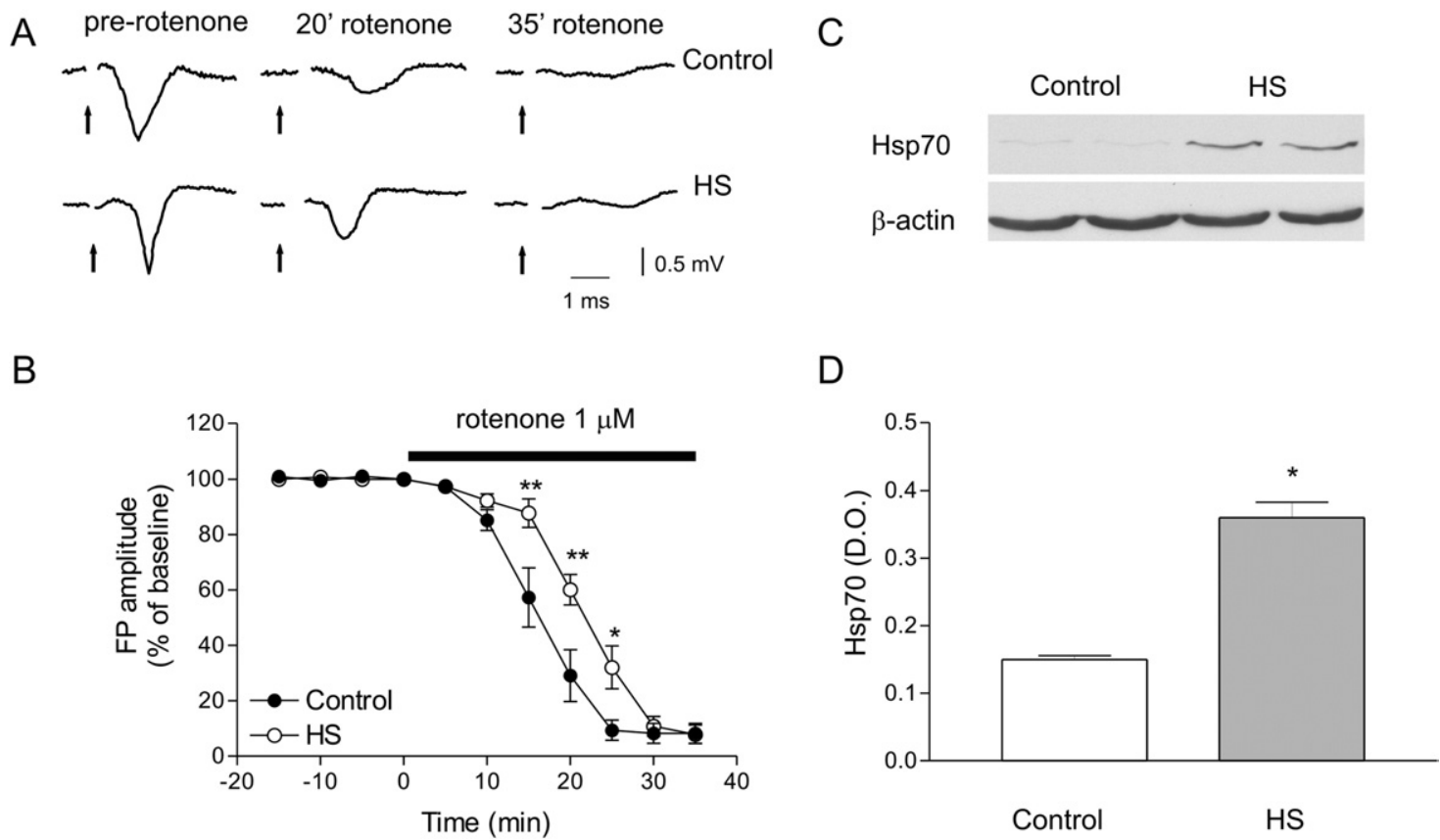

Fig. 2. Hsp70 overexpression reduces the irreversible field potential changes induced by rotenone. (A) Traces of a field potential recorded before, at $20 \mathrm{~min}$, and at $35 \mathrm{~min}$ after application of $1 \mu \mathrm{M}$ rotenone in a corticostriatal slice preparation from control or HS rats. (B) Time course of the field potential amplitude in presence of $1 \mu \mathrm{M}$ rotenone in corticostriatal slice preparations from control and $\mathrm{HS}$ rats; ${ }^{*} P<0.05$, ${ }^{* *} P<.01$. (C) Representative Western blot showing Hsp70 overexpression in corticostriatal slice homogenate of HS rats versus euthermic controls. Expression of $\beta$-actin was also analyzed as loading control. (D) Bar graph of Hsp70 densitometric data in pooled corticostriatal slice homogenates from control $(n=3)$ or HS ( $n=4)$ rats. Data are mean \pm SEM * $P<0.05$. 
A

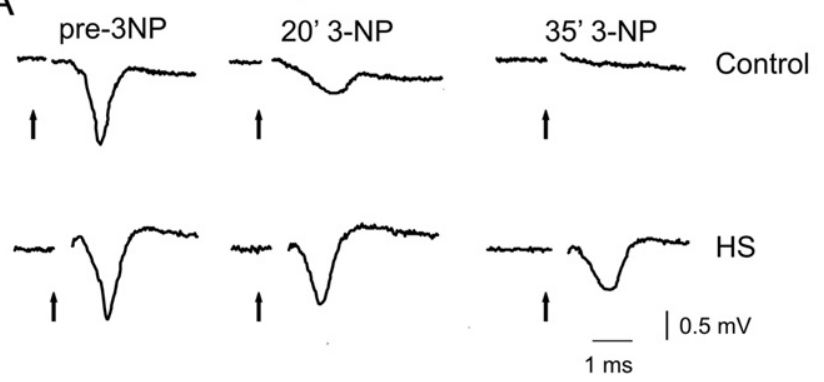

C

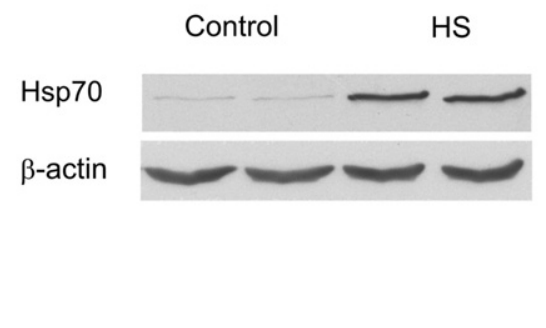

B

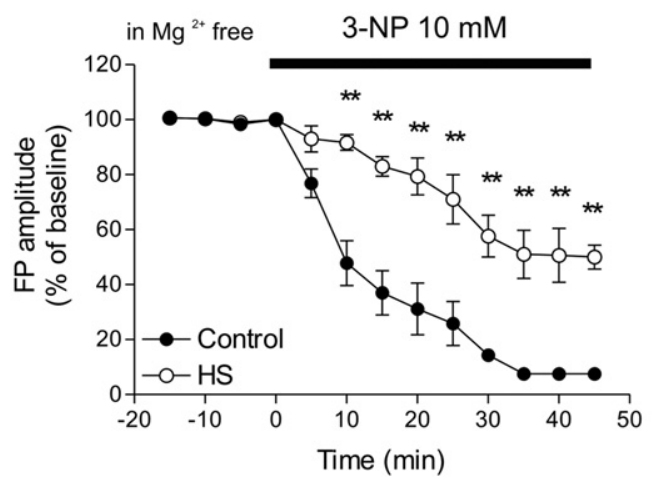

D

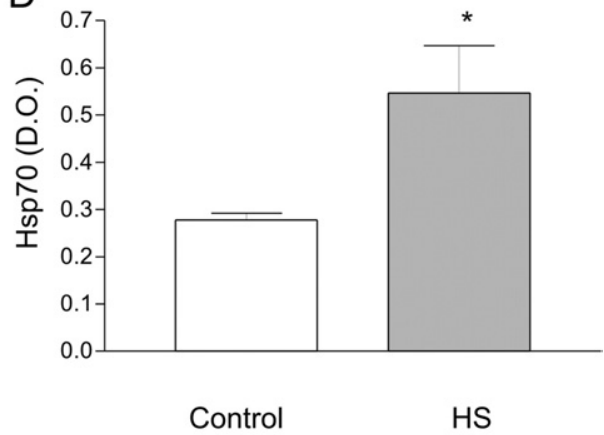

Fig. 3. Hsp70 overexpression reduces the irreversible field potential changes induced by $3-N P$. (A) Traces of a field potential recorded before, at 20 min, and at $35 \mathrm{~min}$ after application of $10 \mathrm{mM}$ 3-NP in a corticostriatal slice preparation from control or HS rats. (B) Time course of the field potential amplitude in presence of $10 \mathrm{mM} 3-\mathrm{NP}$ in corticostriatal slice preparations from control and HS rats; ${ }^{* *} P<.01$. (C) Representative Western blot showing Hsp70 overexpression in corticostriatal slice homogenate of HS rats versus euthermic controls. Expression of $\beta$-actin was also analyzed as loading control. (D) Bar graph of Hsp70 densitometric data in pooled corticostriatal slice homogenates from control ( $n=3$ ) or HS ( $n=4)$ rats. Data are mean \pm SEM * $P<0.05$.

the present study we carried out the electrophysiological analysis $4 \mathrm{~h}$ after the heat shock. In fact, a significant increase in hsp70 has been detected between 1.5 and $6 \mathrm{~h}$ after hyperthermia (Krueger-et al, 1999). Conversely, hsp25/27 was expressed only $24 \mathrm{~h}$ following such stress (Krueger-Naug et al., 2000; Franklin et al., 2005).

To explain the molecular mechanisms underlying hsp70mediated cellular protection against rotenone and 3-NP neurotoxicity, several possibilities can be envisaged, considering that a complex combination of molecular events mediates cell death when mitochondrial energy metabolism is impaired. In both cases, energetic deficit and oxidative stress result in disrupted ionic homeostasis, irreversible membrane depolarization, increased intracellular calcium, lowered intracellular $\mathrm{pH}$, kinase activation, increased free radicals, and misfolding and aggregation of many proteins including enzymes and constituents of cytoskeletal and contractile structures.

Hsp70 protects ATP-depleted cells from rapid necrotic death by inhibiting the aggregation of cytoskeletal proteins. This idea is supported by the results of studies on the phenomenon of cell resistance to prolonged energy deprivation after mild thermal stress that were carried out in murine tumor cells treated with rotenone to block ATP generation (Kabakov et al., 2002). In these cells, in which ATP rapidly decreased to $3-6 \%$ of the initial level, a rapid necrotic death was directly correlated with aggregation of cytoskeletal proteins and membrane damage. After mild thermal stress diminution in aggregated insoluble proteins was coupled with the delay of rotenone-induced necrotic death in these cells overexpressing hsp70.

Resistance to both mitochondrial toxins of slices overexpressing hsp70 could be ascribed in great part to the protective action exerted by the chaperone against the oxidative stress secondary to inhibition of mitochondrial complex I or complex II (Betarbet et al., 2000). This hypothesis is corroborated by several studies focused on the role of hsp70 in reducing mitochondria impairment-dependent oxidative stress (Lee et al., 2001). On the other hand, cases exist in which hsp70 overexpression does not protect against mitochondrial neurotoxins. For example, in hippocampal cell cultures, while overexpression of hsp70 protected neurons against a heat shock, it did not protect against 3-NP neurotoxicity (Fink et al., 1997).

Astrocytes from hsp70 transgenic mice were protected from oxidative stress produced by hydrogen peroxide in a dose-dependent manner and, to a lesser extent, by glucose or combined glucose-oxygen deprivation, confirming that the protective effects of the overexpressed protein are related to the nature and severity of the insults (Lee et al., 2001). In line with the aforementioned data, it has been demonstrated that hsp70 transfection can significantly prevent rotenone-mediated mitochondrial inhibition and oxidative stress and rotenone-mediated $\alpha$-synuclein aggregation in mesencephalic/ neuroblastoma hybrid cells (MES) cells (Zhou et al., 2004).

An additional function of hsp70 in protecting cells from rotenone and 3-NP toxicity can be expressed in terms of facilitation of the intracellular trafficking of polypeptide 
chains destined for post-translational insertion into organelle membranes by preventing them from aggregation and/or by transporting them to the translocation pore. In particular, considering that part of the subunits of mammalian complexes I, III, IV and V and all the subunits of complex II, cytochrome $\mathrm{c}_{1}$, and citrate synthase are encoded for by nuclear DNA (Johns, 1996), an hsp70-mediated protection/enhancement of mitochondrial respiratory chain may be exerted primarily by positively influencing both the translation and import of nuclear-encoded protein in the mitochondria. This hypothesis was first advanced on the basis of findings from studies in which myocardial tolerance to prolonged ischemia and reperfusion was investigated in both heat-stressed and hsp70-transfected animal hearts (Sammut and Harrison, 2003). On the whole, this hypothesis fits with our data showing hsp70-mediated resistance against rotenone and 3-NP cytotoxicity in corticostriatal slices and could explain the greater resistance of corticostriatal slices to 3-NP with respect to rotenone. The 3-NP, as inactivator of succinate dehydrogenase, inhibits both the Krebs cycle and complex II of the mitochondrial electron transport chain (Coles et al., 1979). Therefore, the high levels of cytosolic hsp70 could have enhanced the energetic capacity of the slices by facilitating both translation and maintenance of the proper folding of both succinate dehydrogenase and subunits of complex II (which are codified by nuclear DNA).

\section{CONCLUSION}

In conclusion, this electrophysiological study, using in vitro application of neurotoxins that model neurodegenerative disorders of the basal ganglia, shows that the induction of hsp70 partially preserves electrical activity during mitochondrial dysfunctions. Interestingly, it has been previously postulated that preserving electrical activity may be crucial in itself in preventing neurons from initiating a cell death program (Michel et al., 2007).

Acknowledgments-The study was supported by Progetti Finalizzati e Strategici Ministero della Salute 2005/2006/2007 (P.C. B.P.), Fondazione Cassa di Risparmio di Perugia (P.C.), HEALTH-200722918, REPLACES (P.C.).

\section{REFERENCES}

Betarbet R, Sherer TB, MacKenzie G, Garcia-Osuna M, Panov AV, Greenamyre JT (2000) Chronic systemic pesticide exposure reproduces features of Parkinson's disease. Nat Neurosci 3:1301-1306.

Brouillet E, Jacquard C, Bizat N, Blum D (2005) 3-Nitropropionic acid: a mitochondrial toxin to uncover physiopathological mechanisms underlying striatal degeneration in Huntington's disease. J Neurochem 95:1521-1540.

Calabresi P, Centonze D, Pisani A, Sancesario G, Gubellini P, Marfia GA, Bernardi G (1998) Striatal spiny neurons and cholinergic interneurons express differential ionotropic glutamatergic responses and vulnerability: implications for ischemia and Huntington's disease. Ann Neurol 43:586-597.

Calabresi $P$, Gubellini $P$, Picconi B, Centonze D, Pisani A, Bonsi $P$, Greengard P, Hipskind RA, Borrelli E, Bernardi G (2001) Inhibition of mitochondrial complex II induces a long-term potentiation of NMDA-mediated synaptic excitation in the striatum requiring endogenous dopamine. J Neurosci 21:5110-5120.
Centonze D, Prosperetti C, Barone I, Rossi S, Picconi B, Tscherter A, De Chiara V, Bernardi G, Calabresi P (2006) NR2B-containing NMDA receptors promote the neurotoxic effects of 3-nitropropionic acid but not of rotenone in the striatum. Exp Neurol 202:470-479.

Coles CJ, Edmondson DE, Singer TP (1979) Inactivation of succinate dehydrogenase by 3-nitropropionate. J Biol Chem 254:5161-5167.

Costa C, Belcastro V, Tozzi A, Di Filippo M, Tantucci M, Siliquini S, Autuori A, Picconi B, Spillantini MG, Fedele E, Pittaluga A, Raiteri M, Calabresi P (2008) Electrophysiology and pharmacology of striatal neuronal dysfunction induced by mitochondrial complex I inhibition. J Neurosci 28:8040-8052.

Craig EA (1993) Chaperones: helpers along the pathways to protein folding. Science 26:1902-1904.

Di Filippo M, Picconi B, Costa C, Bagetta V, Tantucci M, Parnetti L, Calabresi P (2006) Pathways of neurodegeneration and experimental models of basal ganglia disorders: downstream effects of mitochondrial inhibition. Eur J Pharmacol 545:65-72.

Fink SL, Chang LK, Ho DY, Sapolsky RM (1997) Defective herpes simplex virus vectors expressing the rat brain stress-inducible heat shock protein 72 protect cultured neurons from severe heat shock. J Neurochem 68:961-969.

Franklin TB, Krueger-Naug AM, Clarke DB, Arrigo AP, Currie RW (2005) The role of heat shock proteins Hsp70 and Hsp27 in cellular protection of the central nervous system. Int $\mathrm{J}$ Hyperthermia 21(5):379-392.

Hirsch EC, Höglinger G, Rousselet E, Breidert T, Parain K, Feger J, Ruberg M, Prigent A, Cohen-Salmon C, Launay JM (2003) Animal models of Parkinson's disease in rodents induced by toxins: an update. J Neural Transm 65:89-100.

Johns DR (1996) The other human genome: mitochondrial DNA and disease. Nat Med 2:1065-1068.

Kabakov AE, Budagova KR, Latchman DS, Kampinga HH (2002) Stressful preconditioning and HSP70 overexpression attenuate proteotoxicity of cellular ATP depletion. Am J Physiol Cell Physiol 283:C521-C534.

Kabakov AE, Gabai VL (1995) Heat shock-induced accumulation of 70-kDa stress protein (HSP70) can protect ATP-depleted tumor cells from necrosis. Exp Cell Res 217:15-21.

Krueger AM, Armstrong JN, Plumier J, Robertson HA, Currie RW (1999) Cell specific expression of Hsp70 in neurons and glia of the rat hippocampus after hyperthermia and kainic acid-induced seizure activity. Brain Res Mol Brain Res 71(2):265-278.

Krueger-Naug AM, Hopkins DA, Armstrong JN, Plumier JC, Currie RW (2000) Hyperthermic induction of the 27-kDa heat shock protein (Hsp27) in neuroglia and neurons of the rat central nervous system. J Comp Neurol 428(3):495-510.

Lee JE, Yenari MA, Sun GH, Xu L, Emond MR, Cheng D, Steinberg GK, Giffard RG (2001) Differential neuroprotection from human heat shock protein 70 overexpression in in vitro and in vivo models of ischemia and ischemia-like conditions. Exp Neurol 170:129-139.

Lu A, Ran R, Parmentier-Batteur S, Nee A, Sharp FR (2002) Geldanamycin induces heat shock proteins in brain and protects against focal cerebral ischemia. J Neurochem 81:355-364.

Mariucci G, Tantucci M, Giuditta A, Ambrosini MV (2007) Permanent brain ischemia induces marked increments in hsp72 expression and local protein synthesis in synapses of the ischemic hemisphere. Neurosci Lett 415:77-80.

Michel PP, Alvarez-Fischer D, Guerreiro S, Hild A, Hartmann A, Hirsch EC (2007) Role of activity-dependent mechanisms in the control of dopaminergic neuron survival. J Neurochem 101:289-297.

Nishizawa J, Nagata K (1999) Regulation of heat shock transcription factors by hypoxia or ischemia/reperfusion in the heart and brain. In: Handbook of experimental pharmacology, Vol. 136 (Latchman DS, ed), pp 201-224. Berlin: Springer-Verlag.

Ota A, Ikeda T, Xia XY, Xia YX, Ikenoue T (2000) Hypoxic-ischemic tolerance induced by hyperthermic pretreatment in newborn rats. $J$ Soc Gynecol Investig 7:102-105. 
Ren M, Leng Y, Jeong M, Leeds PR, Chuang DM (2004) Valproic acid reduces brain damage induced by transient focal cerebral ischemia in rats: potential roles of histone deacetylase inhibition and heat shock protein induction. J Neurochem 89:1358-1367.

Sammut IA, Harrison JC (2003) Cardiac mitochondrial complex activity is enhanced by heat shock proteins. Clin Exp Pharmacol Physiol 30:110-115.

Saulle E, Gubellini P, Picconi B, Centonze D, Tropepi D, Pisani A, Morari M, Marti M, Rossi L, Papa M, Bernardi G, Calabresi P (2004) Neuronal vulnerability following inhibition of mitochondrial complex II: a possible ionic mechanism for Huntington's disease. Mol Cell Neurosci 25:9-20.
Sittler A, Lurz R, Lueder G, Priller J, Lehrach H, Hayer-Hartl MK, Hartl FU, Wanker EE (2001) Geldanamycin activates a heat shock response and inhibits huntingtin aggregation in a cell culture model of Huntington's disease. Hum Mol Genet 10:1307-1315.

Tozzi A, Costa C, Di Filippo M, Tantucci M, Siliquini S, Belcastro V, Parnetti L, Picconi B, Calabresi P (2007) Memantine reduces neuronal dysfunctions triggered by in vitro ischemia and 3-nitropropionic acid. Exp Neurol 207:218-226.

Zhou Y, Gu G, Goodlett DR, Zhang T, Pan C, Montine TJ, Montine KS, Aebersold RH, Zhang J (2004) Analysis of alpha-synucleinassociated proteins by quantitative proteomics. J Biol Chem 279:39155-39164.

(Accepted 29 June 2009)

(Available online 4 July 2009) 